\title{
Introducing Future Educators to GIS Data Collection
}

\author{
Francis Stonier \\ University of West Georgia, USA
}

\begin{abstract}
This paper shares the first-time geographic information system (GIS) introduction, experiences, and reactions of students from three Social Studies Methods Courses in the fall of 2014 and spring of 2015. The professor has been formally training educators in some of the classroom uses of GIS through grant funded workshops. Recently he decided to expose pre-service teachers to GIS through field data collection and analysis in a methodology course. Participants had a very successful educational experience using their own personal mobile devices to map various aspects of their campus.
\end{abstract}

\section{Introduction}

In the fall of 2014 and spring of 2015 , PK-5 preservice teachers were introduced to geographic information systems (GIS) in a social studies methodology course. The instructor has been training area educators in the classroom use of GIS since 2013. GIS can provide students an opportunity to display and interact with geospatial information through the use of computers and mobile devices. This work shares some of the experiences of those students as well as some of the observations of professor. So far GIS has been well received by the students with several expressing an interest in learning and using more GIS in their future classrooms.

\section{Background}

GIS can help promote contextually rich student learning [1] and is well adapted to fostering K-12 students' critical thinking [2] and spatial thinking skills [3]. The underlying theoretical framework for these activities has been based off the concept of integrating technology, pedagogy, and content knowledge (TPACK) developed by Mishra and Koehler [4]. Essentially in this case, TPACK is promoting successful technology integration though appropriate understanding and appropriate instructor pedagogy. With the exception of only a single student who had done a traditional field data collection with a GPS unit prior to college, this was their first experience with GIS, affording them a relatively unique opportunity to conduct field data collection.

\section{Method}

The week prior to the actual mapping activity the professor introduced the classes to GIS by sharing example maps [5] and a portion of a video from the Esri 2014 User conference [6]. The maps allowed students to view various map layers and how analysis can be performed on the data contained within the maps. The video provided some real life examples of how elementary school children are using maps to approach real world issues and investigate the world around them.

Class one served as a pilot group for which basic maps and a class survey were generated. Reflections helped improve the maps and instruction for classes 2 and 3 in the spring of 2015. The same general premise was used with the maps for all groups such as beverage choice and campus items to map. However, improvements were made in terms of what data could be supplied by the participants in the later maps. This change was made to allow for stronger data analysis to occur. Improvement was also made in terms of group guidelines. Groups were formed in advance by the professor based on a separate group project assignment already within the course. However, the instructor provided groups with stronger suggestions of how to manage groups in an effort to yield more accurate data within the assigned group map sections.

Using their own personal mobile devices, students downloaded the free ArcGIS app and began mapping within the classroom. A map was constructed by the instructor where participants could map their favorite morning beverage as well as the place they were born. When a point was mapped students could select from a wide variety of beverage choices and quantity generally consumed. There was also the option to type in additional notes about their selection if desired. While students were mapping, the professor would have the class map up on the main screen where it could be seen that points were populating live. 


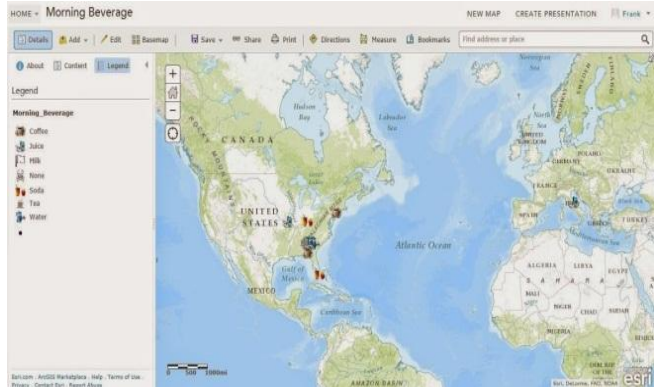

Figure 1. Morning beverage map showing preferred morning beverage, amount, and place of birth

The resulting map would yield a visual representation of where all of the students in class were born as well as beverage data. The beverage data would be analyzed to provide a basic view of how GIS field data collection can yield reportable findings. See Figure 1 below.

For the campus mapping, students were divided into a history, geography, economics, or civics group. See Figure 2 below. Each group was assigned to a color coded zone of campus they were to map within. Zones were not necessarily equal in size but tailored to suit the geography of the campuses and areas students could access. It was suggested that groups utilize individuals or partners to map either a specific portion of their color zone or to attempt to map all or a greater portion of a specific items such as lighting, plant life (see Figures 3 and 4), security boxes, vehicles, wildlife (see Figure 5), or seating within their color zone. In an effort to help make a realistic connection, the professor provided potential mock scenarios; such as, the campus police want to ensure there is adequate lighting for students at night, the sustainability council would like trees to be mapped to see if there is need for further planting, etc. With each item mapped there was a variety of numerical data that could be added as well as photographs of the actual item. As the intention was to reconvene to perform some basic analysis of the campus map it was necessary to set a time for all to meet back in the classroom.

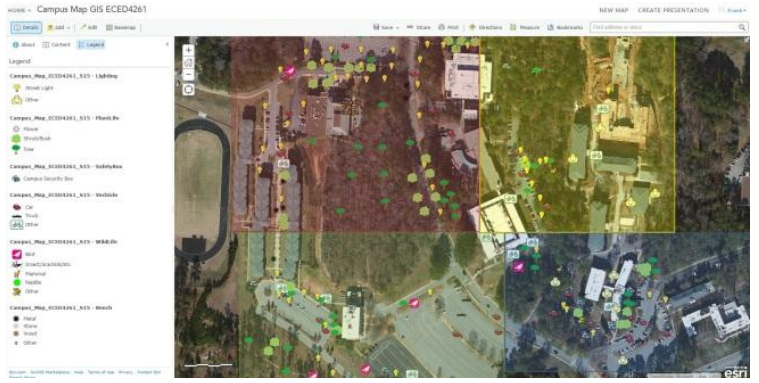

Figure 2. Field data collection on campus within assigned zones

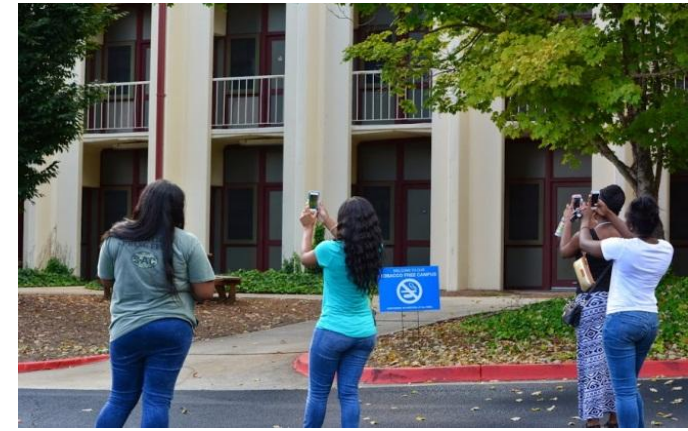

Figure 3. Students mapping plant life and seating data on campus: benches and trees

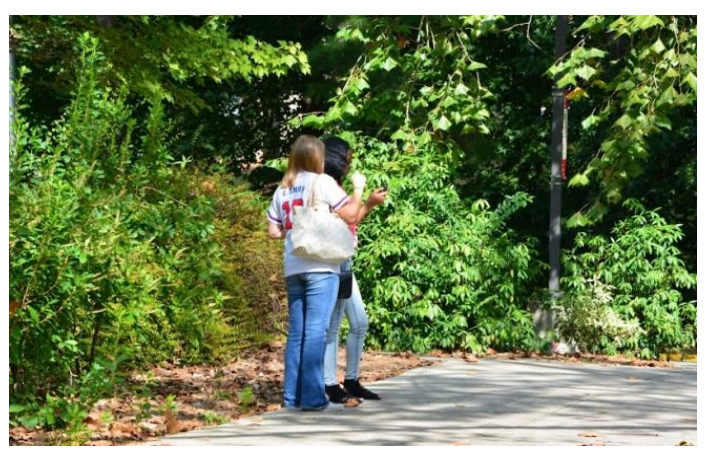

Figure 4. Students mapping plant life data on campus: flowers, shrubs/bushes, and trees

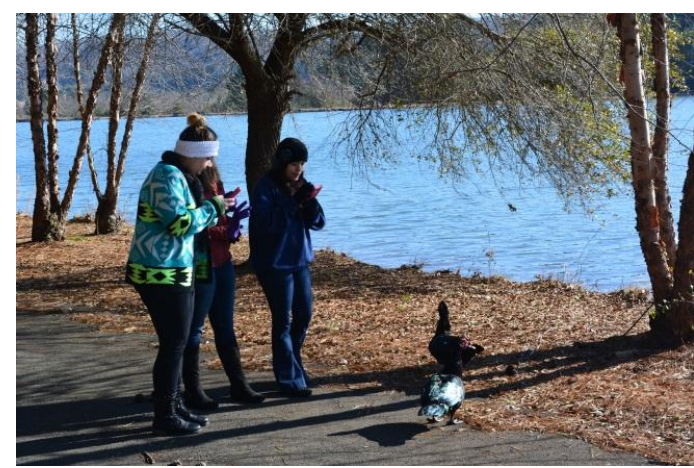

Figure 5. Students mapping wildlife data on campus: birds, insects/arachnids/etc., mammals, reptiles, and other

\section{Setting and Participants}

This project was conducted at a south-eastern university in the United States. Participants were preschool to grade five pre-service teachers. The activity and follow-up reflection was conducted as a course assignment. Participants were three complete classes of undergraduate social studies methods. Class one had 18 students, class two held 39 students, and class three 13 students. Class three was comprised of students who attended the university at a satellite location approximately an hour north of the main campus. As such, their campus map was tailored to suit the satellite location. Due to weather and class size a single group area was used, instead of four as were used on the main campus. 


\section{Analysis}

The students were asked a series of eight followup questions about their experience. The survey asked about their experiences, the importance of accurate data collection, and potential classroom use. Responses were reviewed and sorted by response. They were then analyzed to identify key themes within and across the classes. Data points were also tallied. Selected student responses have also been included within results.

\section{Results}

With the exception of one student who had an experience using GPS units in high school this was their first time collecting GIS data. Some students reported that the process could be somewhat confusing at first but all were successful with additional practice and/or support. The main theme was ease of use.

Question 1: Was this your first time collecting Geographic Information Systems (GIS) data? If so, describe how easy/difficult it was for you to do so? What made it so easy/difficult and how could this be repeated/fixed? If not, please describe the above but also share what GIS data you have collected in the past and how it was being used.

"This was the first time I have collected Geographic Information Systems data. I enjoyed how easy it was to navigate the app on the iPhone! Once I played around with it for a moment, it was very easy to accomplish tasks. The simple accessibility of the app was very beneficial as well. Young students wouldn't have many issues using the technology after it is explained."

"This was my first time collecting GIS data. I thought that it was easy to collect the data on my phone app. It was also a little easier because I was in a group and had other people to help me."

"Yes this was my first time collecting GIS data. The app was confusing to begin with. After working with the app for a while it became easier to use. Letting students practice with the app for a little while, like we did, is a really good idea."

The most substantial theme that arose was that they enjoyed being able to get out of the classroom and work outside. Several expressed specifically that the activity was highly engaging. All 70 student responses were positive concerning their experiences with the field data collection.
Question 2: Please describe your experience with field data collection during this week's class.

"My experience with collecting field data was great. It was a lot of fun to get out of the classroom and plot points around campus. I thought it was cool that you could see everyone else plotting at the same time. I really enjoyed getting to use the GIS data."

"It was actually a lot of fun! I was hesitant at first, but it was fun to go outside and actually look around campus. I often think we are always in a hurry and don't pay too much attention to the things around us. After we got done mapping it was cool to see all the things that are on campus."

"I enjoyed the experience. It was a nice change to get to go outside, although it was a little chilly. I also liked that we were able to work in groups for this assignment. It was interesting to see all the different plotted points on campus as a whole. I would probably use GIS in my future classroom."

"My experience with this technology was very enlightening. I felt as if I wasn't in class but out in the real world experiencing this first hand. I think it was great idea for the class."

There were a few students who had difficulty due to phone battery life or Wi-Fi issues. However, as they were in groups, everyone was able to continue by sharing their functional technologies together. A key theme with the satellite campus group (class 3) was the weather. The day data collection occurred was surprisingly cold for our area, so they participated in the activity for a shorter period of time and in a more limited area. Another main theme for improvement was using a class set of devices. The decision was made not to do this as the data collection would have to be done offline due to campus Wi-Fi not extending far beyond buildings for example in wooded areas. Offline data collection would have been far more complex and likely not as accurate with most if not all groups. Another major theme for improvement was adding more items that could be located.

Question 3: What could be done to improve the field data collection experience?

"My only suggestion for improving the field data collection experience is to probably check out a class set of iPads for students to use. Some people had problems with their device and probably did not get as good of an experience as everyone else. I'm suggesting this also because the directions in the beginning were confusing because we noticed that everyone's app was different and worked differently." 
"Maybe doing this assignment on a warmer day could have improved the experience. Since we were already broken up into teams, we could have turned it into a challenge of some sort with a small reward to the winning group. Although the experience was fun, this would have made it much more exciting."

"I found this activity to be very enjoyable and have no complaints on this lesson. The only thing I might add is to have more emoji/items for us to locate. For example, maybe adding a recreational icon for things like playgrounds or volleyball/tennis courts. Or even adding a maintenance icon for things like garbage or food services. This would just give us more things to locate, take pictures of, and pinpoint on our GIS map."

Majority of the responses centered on scenarios shared at the start of the activity. However, the theme arose with a small number (five different students) concerning measuring distance. Measurement is a feature available within the app but was not discussed with the class or individuals.

Question 4: What could be done with the data we collected? Should we have collected more data about each point? If so what? If not why not?

"We could have calculated the percentage of trees on campus. We could have also determined if there needs to be more parking on campus and where it could go. If we were looking at parking we would to have taken more varied data. For example, we'd need to look for all the cars but at different times of day."

"The data that we collected could be used in many different ways. One way that I would use this data in my classroom would be to have the students create a graph to show the different data that was collected. Another way that we could use this data would have been in a math lesson by having the student's measure out the distance between two different points that they graphed."

"From this experience, the data we collected could be used for many things. It could help our school come up with better ways for managing parking. This data could also help students know where trees, wildlife, and plants are for recreational enjoyment. I think when collecting this data, we could have wrote a little more in the description. For example, for parking, we could have given an exact number of parking spaces and how many were occupied at the time of the day. For benches, we could have documented how many were in a given area and what condition they were in. I think providing more detail would only be more beneficial for anyone who would actually be using the data we collected to improve our campus and facilities."

It was clear from all students that they felt it was important to collect accurate data so that appropriate decisions or understandings could be made from it. Majority of students approached the question in the context of a future data collection. One example has been shared where the student has considered present and future.

Question 5: How important is it for accurate data to be collected? Why or why not?

"I believe it is extremely important to collect accurate data. What would be the point in collecting incorrect information? Any conclusions made from that data would be skewed and useless."

"It is important for the data to be accurate if you were going to use it for something serious like improving our campus. If we needed to know where to add specific things like street lights, we would need to plot those points accurately. For example if we were to plot a street light where there was not a street light, that would mess up our data. If our data is inaccurate, a street light might not be added in a place where we really need it."

"For what we did in class, I do not think the information has to be very accurate. We were just figuring out the app and mapping stuff. If we were going to use the map created to try and change something or write a letter to someone, then the data would need to be very accurate. The data collected should be accurate, when using the data for important tasks."

The majority of students felt that students in third grade or above could be successful with field data collection. Only two felt it should be used just with students older than the elementary age.

Question 6: What age of student could/should do field data collection? Why?

"I would say $3^{\text {rd }}$ grade and up. You would want to start this activity with a group of students familiar with technology and that had the technology to do this."

"I would only allow the upper elementary age and up to do field data collections. I say this because third grade is when most students have the basics of how to read, write, and understand the material you give to them. They are also at an age when they are curious about the world around them and would be excited to get out of their desk for a while." 
"I think students should start collecting field data in $2^{\text {nd }}$ or $3^{\text {rd }}$ grade, but I would make them stay in a fenced in area with a teacher having eyes on all the students. Volunteer parents would also help control the actions of students. I think younger grades would not understand the purpose of the lesson and get too excited about being able to run around outside. They need to be older to be able to cross traffic and they are more familiar with signs and observations in the area."

There were a wide variety of potential classroom uses shared. The most frequent theme was mapping in or around their schools. These maps would focus on safety, landscape, equipment, playgrounds, or recycling. Classroom ideas mainly focused on science or social studies themes though there were a few examples of integrating writing into the lesson by following up by writing letters to the appropriate authority to resolve issues that might be mapped. Some specific themes mentioned were mapping regions and habitats, local neighborhoods to identify culture and even potential problems, life cycles (trees, plants, frogs, birds, and insects), mapping habitats zoos, science physical attributes, and cardinal directions.

Question 7: Pretend you were going to teach a lesson using GIS field data collection similar to what we did today with students. What kind of map would you design? What standards would you target?

"I would design a map around the school. I would use the standard about recycling and have the students walk around the school and look for trash and label it. We would spend a few days cleaning up the trash and encouraging other students to throw their trash away and recycle more. After a week has passed, we will walk around the school and plot points where we find trash just lying around. Hopefully, there would be little to no trash after a week compared to when we started. We would keep doing this once a week until we are satisfied with the amount of change that has occurred just from our project."

"I think that it would be fun to map the school and do a project on fire/emergency safety. You could document all the windows, openings, and doorways to know where not to be during a storm. You could also document where classrooms are and how many students/people are in each room. You could use the correlation between safe places and students and find the safest and most efficient places to go during an emergency. Although this doesn't match a standard, it is something important for students to know."

"Since I am in third grade right now, I would use this to teach my students about earth science. I would have the same layout as we did in class such as mapping out four sections and dividing the class into four groups so there would be six students in each group. I would have them map out things such as rocks, plants, trees, leaves, and different types of soil and grass. This would give them a better understand of the world around them."

Of the responses provided, the key theme was that the students plan to use GIS in their future classrooms. All responses for question eight were positive, blank, or simply stated there was nothing to add.

Question 8: Is there anything else you would like to add?

"This is a very interesting lesson that I hope to be able to use in my future classroom."

"I do not think I need to add anything else. The GIS experience was really good. The app is really interesting and beneficial to students and teachers."

"No there is nothing I would add. I really enjoyed this activity and these questions have made me think even more about how I could introduce this to my kids."

"No I feel like this activity was a great activity to do with students. I cannot wait for one day to incorporate this into my lesson plans."

Over the three classes 375 data points were collected. See Table 1 below.

Table 1. Data points mapped over three classes

Lighting Plant Life Safety Box Vehicles Wildlife Seating

\begin{tabular}{lllllll}
\hline Class 1 & 20 & 27 & 6 & 16 & $\mathrm{n} / \mathrm{a}$ & 15 \\
Class 2 & 68 & 93 & 11 & 49 & 18 & 29 \\
Class 3 & 4 & 7 & 1 & 2 & 4 & 5 \\
\hline
\end{tabular}

\section{Discussion}

Class 1 provided valuable feedback on the success of the activity as well as how the activity could be improved for future students. In general most felt they were well oriented to field data collection through the first map on morning beverages. However, a few suggested assigning more specific group member roles such as one student is responsible for identifying all lights while another only security boxes, etc. As these students were all in their third year of study the researcher assumed they would be well oriented to their campus. However, some suggested walking the portions of campus to be 
mapped in advance. This could be attributed to some students being commuter students, some only being familiar with the parking, walkways, or bus stops and the education buildings, also the unfamiliarity of students using maps in general to navigate their location. Further consideration was given to future classes in this regard. After having more practice with the technology itself, legends were improved, as well as, potentially better images selected, and the category of wildlife was added.

The purpose of this activity was to introduce the students to this technology, see what worked and what did not, find out if the participants felt this technology could or should have a place in their future classrooms, and overall if the activity was an effective use of class time. There were some glitches; however, all of the students still had an opportunity to participate. The experience was a resounding success for the professor as well as the students. It is an activity that will continue to be used by the professor and improved where appropriate.

As the shared campus map is populated with live data points it is possible for users, in particular the instructor, to have a fairly accurate location of where students are mapping even if the distance away is significant. This would allow for the professor to keep an "eye" on all the students, as well as, move between groups to offer support and photograph student efforts. This ability to know where one's students are would be essential in an off campus setting. Due to this ability to somewhat track the students, they were allowed the freedom to conduct their work without having to be immediately supervised by the professor at all times. The construction of the class map can be somewhat technical, though once constructed, is relatively simple for users to interact with the map using the ArcGIS or Collector apps.

\section{Conclusion}

It is a concern that presently only students under this professor would have the opportunity to experience GIS (in this fashion) during their methodology courses. Efforts are currently underway to expose other education faculty to field data collection as well as other GIS methods. Currently the instructor is working with three honors students to help them develop inquiry-based lessons and activities using GIS. Depending on what is produced, there is potential for further research and presentation with the students, as well as, the potential for real use of GIS in their future classrooms. The professor has also been approached about developing and leading a GIS curriculum with local elementary and middle school students within an afterschool program in the fall. There was also a brief mention of the efforts made with class 1 in Esri's Lighthouses of GIS Use in K12 Education [7].
Consideration is being made towards developing a GIS in Education course that could be taken as an elective or special topics course.

Awareness of GIS is likely in greater need than even the skills to use it. Esri has made efforts to make access in US public schools essentially a nonissue with ArcGIS Online and their free organization accounts. However, relatively few (but a growing number of) educators seem to be aware of or utilizing this technology. There are certainly skills needed and learning curves depending on how substantial the activities one chooses to pursue. However, this researcher is hopeful that GIS use will eventually become common place in the modern classroom and included within national and/or more state curriculums.

\section{References}

[1] T.R. Baker and S. H. White, "The Effects of G.I.S. on Students' Attitude, Self-efficacy, and Achievement in Middle School Science Classrooms", Journal of Geography, 102(6), 2003, pp. 243-254.

[2] T.C. Patterson, "Google Earth as a (Not Just) Geography Education Tool”, Journal of Geography, 106(4), 2007, pp.145-152.

[3] National Research Council. (2006). "Learning to think spatially: GIS as a support system in the K-12 curriculum", National Academies Press, Washington, DC, 2006.

[4] P. Mishra and M. Koehler, "Technological pedagogical content knowledge: A framework for teacher knowledge", Teachers College Record, 108 (6), 2006, pp. 1017-1054.

[5] J.E. Hong and F. Stonier, "GIS In-service Teacher Training Based on TPACK", Journal of Geography. Advance online publication. doi: 10.1080/00221341.2014.947381, 2014.

[6] Esri, Connecting GIS with Education, 2014 Esri User Conference, http://video.esri.com/watch/3665/connectinggis-with-education, January 19, 2015.

[7] Esri, Lighthouses of GIS Use in K12 Education, GIS in US K12 Education, http://edgis.org/storymaps/usk12gis2/, January 12, 2015. 